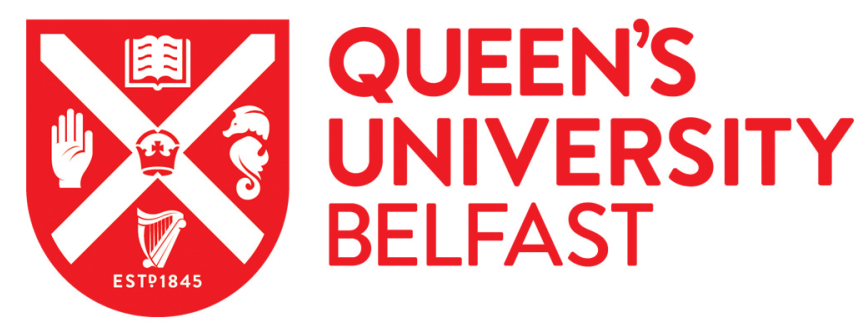

\title{
Punctal plug: a medical device to treat dry eye syndrome and for sustained drug delivery to the eye
}

Yellepeddi, V. K., Sheshala, R., McMillan, H., Gujral, C., Jones, D., \& Singh, T. R. R. (2015). Punctal plug: a medical device to treat dry eye syndrome and for sustained drug delivery to the eye. Drug Discovery Today, 20(7), 884-889. https://doi.org/10.1016/j.drudis.2015.01.013

\section{Published in:}

Drug Discovery Today

\section{Document Version:}

Peer reviewed version

\section{Queen's University Belfast - Research Portal:}

Link to publication record in Queen's University Belfast Research Portal

\section{Publisher rights}

(c) 2015, Elsevier. Licensed under the Creative Commons Attribution-NonCommercial-NoDerivatives 4.0 International

$\mathrm{http}: / /$ creativecommons.org/licenses/by-nc-nd/4.0/ which permits distribution and reproduction for non-commercial purposes, provided the author and source are cited.

\section{General rights}

Copyright for the publications made accessible via the Queen's University Belfast Research Portal is retained by the author(s) and / or other copyright owners and it is a condition of accessing these publications that users recognise and abide by the legal requirements associated with these rights.

Take down policy

The Research Portal is Queen's institutional repository that provides access to Queen's research output. Every effort has been made to ensure that content in the Research Portal does not infringe any person's rights, or applicable UK laws. If you discover content in the Research Portal that you believe breaches copyright or violates any law, please contact openaccess@qub.ac.uk. 


\section{Accepted Manuscript}

Title: Punctal plug: a medical device to treat dry eye syndrome and for sustained drug delivery to the eye

Author: Venkata K. Yellepeddi Ravi Sheshala H. McMillan

C. Gujral D. Jones T. Raghu Raj Singh

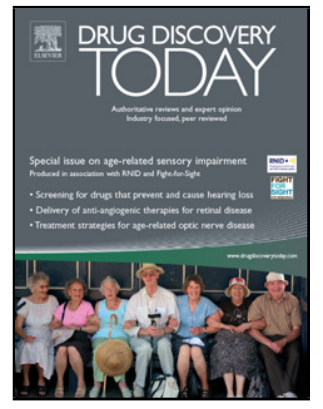

PII:

S1359-6446(15)00064-1

DOI: http://dx.doi.org/doi:10.1016/j.drudis.2015.01.013

Reference: DRUDIS 1576

To appear in:

Received date: $\quad 23-9-2014$

Revised date: 13-1-2015

Accepted date: $\quad 30-1-2015$

Please cite this article as: Yellepeddi, V.K., Sheshala, R., McMillan, H., Gujral, C., Jones, D., Singh, T.R.R.,Punctal plug: a medical device to treat dry eye syndrome and for sustained drug delivery to the eye, Drug Discovery Today (2015), http://dx.doi.org/10.1016/j.drudis.2015.01.013

This is a PDF file of an unedited manuscript that has been accepted for publication. As a service to our customers we are providing this early version of the manuscript. The manuscript will undergo copyediting, typesetting, and review of the resulting proof before it is published in its final form. Please note that during the production process errors may be discovered which could affect the content, and all legal disclaimers that apply to the journal pertain. 
1 Punctal plug: a medical device to treat dry eye syndrome and for sustained 2 drug delivery to the eye

3 Venkata K. Yellepeddi ${ }^{1,2}$, Ravi Sheshala ${ }^{3}$, H. McMillan ${ }^{4}$, C. Gujral ${ }^{4}$, D. Jones ${ }^{4}$ and T. Raghu Raj 4 Singh $^{4, *}$

$5 \quad{ }^{1}$ College of Pharmacy, Roseman University of Health Sciences, South Jordan, UT, USA

$6{ }^{2}$ Department of Pharmaceutics and Pharmaceutical Sciences, University of Utah, Salt Lake City, 7 UT, USA

$8{ }^{3}$ Department of Pharmaceutical Technology, School of Pharmacy, International Medical

9 University, Bukit Jalil, 57000 Kuala Lumpur, Malaysia

$10{ }^{4}$ School of Pharmacy, Queen's University Belfast, Medical Biology Centre, 97 Lisburn Road, 11 Belfast BT9 7BL, UK

12 Keywords: Punctal plug; dry eye syndrome; SmartPLUG ${ }^{\mathrm{TM}}$; silicone; bacterial conjunctivitis;

13 drug-loaded punctal plugs.

14 Teaser: Punctal plugs are miniature medical devices used for the treatment of a variety of ocular 15 diseases either by punctual occlusion or by providing sustained delivery of drugs to the eye.

16

17 "Corresponding author: Singh, T.R.R. (r.thakur@qub.ac.uk). 
19 Punctal plugs (PPs) are miniature medical implants that were initially developed for the 20 treatment of dry eyes. Since their introduction in 1975, many PPs made from different materials

21 and designs have been developed. PPs, albeit generally successful, suffer from drawbacks such

22 as epiphora and suppurative canaliculitis. To overcome these issues intelligent designs of PPs

23 were proposed (e.g. SmartPLUG ${ }^{\mathrm{TM}}$ and Form $\mathrm{Fit}^{\mathrm{TM}}$ ). PPs are also gaining interest among

24 pharmaceutical scientists for sustaining drug delivery to the eye. This review aims to provide an

25 overview of PPs for dry eye treatment and drug delivery to treat a range of ocular diseases. It 26 also discusses current challenges in using PPs for ocular diseases.

27 


\section{Introduction}

29 Ocular diseases range from a simple inflammation (e.g. conjunctivitis) to serious loss of vision

30 (e.g. age-related macular degeneration). Depending upon the origin of ocular disease, drug

31 delivery can be achieved through different routes such as topical, transscleral and intravitreal.

32 Drug delivery to the eye can also be classified anatomically into two segments, namely anterior

33 and posterior segment drug delivery. Ocular diseases if left untreated can lead to partial or

34 complete loss of vision. For example, anterior segment diseases that can cause serious vision

35 impairment include eyelid anomalies (e.g. Sjögren's disease, injuries, radiation or mucin

36 deficiency), glaucoma, bacterial keratitis, uveitis, herpes simplex keratitis, refractive surgery,

37 blepharitis and dry eye syndrome (DES) or keratoconjunctivitis. Similarly, chronic posterior

38 segment diseases such as diabetic retinopathy, diabetic macular edema, age-related macular

39 degeneration and other chorioretinal diseases can lead to vision impairment or blindness if left

40 untreated.

41 Development of therapeutics for treatment of ocular diseases is a challenging task for

42 pharmaceutical formulators and scientists. This is because of the sensitivity of the ocular tissues

43 and the presence of various physicochemical and biological barriers for drug delivery. Of the

44 different routes of drug delivery, topical administration (e.g. eye drops) remains the most widely

45 accepted and preferred route of administration because of its ease of access and patient

46 compliance. However, the bioavailability of topically administered drugs is compromised by

47 factors such as blinking, tear production and barrier function of the cornea, which allows only

$481 \%$ or less of the total dose to be administered. Thus, drug delivery modalities that can increase

49 drug bioavailability (extending the duration of release, decreasing the amount of drug delivered, 
50 minimizing systemic exposure and improving patient compliance and adherence) will certainly

51 offer many advantages over conventional eye drops [1,2]. Some of these approaches include use

52 of mucoadhesives, prodrugs, nanospheres, liposomes, inclusion of permeability enhancers,

53 implants and punctal or punctum plugs (PPs). This review will focus on the ocular applications

54 of PPs. First, it reviews the use of PPs as a medical device initially developed to physically block

55 the puncta of the eye to treat DES. Second, it reviews the application of PPs for drug delivery to

56 the anterior segment of the eye.

\section{Dry eye syndrome}

58 DES or keratoconjunctivitis sicca is one of the most common ocular disorders frequently

59 discussed in the office of eye-care specialists. In the USA, the average annual cost of managing a

60 patient with DES was US\$783 (or US\$3.3 billion in total) in 2011. Furthermore, from a societal

61 perspective it was estimated that DES costs US\$11 302 per patient (or US\$55.4 billion overall)

62 in the USA [3]. The symptoms of DES often include dryness, photophobia, burning and stinging,

63 itching, eye fatigue, pain and redness (hyperemia) [4,5]. DES is estimated to affect between 14\%

64 and $33 \%$ of the population worldwide, henceforth it is a significant public health concern [6].

65 The pathophysiology of DES usually includes poor production of the ocular tear film and

66 evaporation of tears. In addition, causes of DES include formation of unstable tear film

67 associated with abnormality of the lipid, protein and mucin profiles and inflammation of the

68 ocular surface and tear producing glands [4]. Better understanding of complex pathophysiology

69 and underlying mechanisms of DES has led to development of numerous pharmacological and

70 nonpharmacological treatment options for DES. However, a detailed discussion on treatment of

71 DES is out of the scope of this review, readers can refer to reviews in the literature [7-11]. 


\section{Treatment of DES}

74 There is no cure for DES but there are treatment strategies to mitigate symptoms. For example,

75 the National Health Service in the UK provides a range of choices for treating DES. The primary

76 nonpharmacological treatment of DES involves the use of tear substitutes, also called artificial

77 tears or lubricant treatment, that consist of a range of drops, gels and ointments. Tear substitutes

78 improve lubrication and enhance humidity at the ocular surface. Tear substitutes usually contain 79 additives such as polymers including carboxy methyl cellulose, polyvinyl alcohol, 80 hydroxypropyl methylcellulose or carbopol 940, which act as lubricants, buffers to maintain the $81 \mathrm{pH}$ of natural human tears $(\mathrm{pH} 7.4)$ and electrolytes to maintain osmolarity [12-15]. However,

82 use of artificial tears will provide short-term symptomatic relief but will not solve the underlying 83 problem with long-term DES: inflammation. In such cases, anti-inflammatory treatments are

84 prescribed such as steroid eye drops and ointments, oral tetracyclines and cyclosporine eye 85 drops. Another alternative in treating DES is the use of PPs, which is discussed in greater detail 86 in the sections below.

\section{PPs for DES and other ocular applications}

88 Punctal or tear duct occlusion involves temporary blocking of the puncta using PPs or permanent 89 blocking by cauterizing [16]. Blocking the punctum results in increased tear fluid accumulation 90 and thus keeps the eye moist. PPs cause occlusion of tear drainage by blocking the tears through

91 the canaliculi, which connects the eye to the nose (Figure 1). Because of their ability in tear 92 preservation, PPs are indicated in certain cases of laser in situ keratomileusis and contact lens 
93 intolerance [17]. It was also reported that insertion of PPs improves tear film stability, tear

94 osmolarity and functional visual acuity in dry eye patients $[18,19]$.

95 Unlike temporary or short-term relief provided by the artificial tears, PPs can provide long-term

96 relief owing to enhanced tear retention and, therefore, enhanced patience compliance. Although

97 developed initially to physically block the puncta, PPs have also been engineered for controlled

98 drug delivery enabling treatment of DES and other anterior ocular conditions [20]. Foulds

99 introduced the first PPs in 1961, which involved dissolvable gelatin implants to block the puncta

100 temporarily [21]. Recently, Qiu et al. reported a clinical study that compared efficacy of PPs

101 versus artificial tears for treating primary Sjögren's syndrome with keratoconjunctivitis sicca.

102 The results indicated that punctal plugs were significantly better at improving dry eye symptoms

103 in comparison with artificial tears [22]. However, in 1975, Freemen developed the modern PP

104 design that was a dumbbell-shaped plug made of silicone. To date, this concept of plug designs

105 remains the prototype and, recently, a number of designs were developed either to enhance plug

106 retention or to provide drug delivery or both [23].

107 PPs are either semi-permanent or temporary depending on the material used for their preparation.

108 Semi-permanent PPs are made using silicone, Teflon ${ }^{\circledR}$, hydroxyethyl methacrylate (HEMA),

109 polycaprolactone (PCL) or polydioxanone; and temporary PPs are made from animal collagen.

110 Semi-permanent PPs either dislodge spontaneously or should be removed by a physician. Plugs

111 fabricated using collagen dissolve within four to seven days; or certain polymer-based plugs last

112 for variable periods of time ranging from three days to six months [13,24,25]. Table 1 lists a few

113 examples of currently marketed PPs that have been fabricated from different materials. For an

114 extensive list readers are requested to refer to [26]. The plugs are either preloaded onto an 
115 applicator or applicator/inserters are provided to aid application into the eye. To facilitate

116 insertion of PPs across the punctum local anesthesia and/or a lubricant is applied.

117 Although insertion of PPs is an effective therapy for treatment of DES many complications are

118 associated with their use. Some of the recognized complications of PPs include epiphora

119 (overflow of tears), suppurative canaliculitis (infection of the lacrimal gland causing surface

120 abnormalities), punctal ring rupture or spontaneous dislodging and abrasion of the corneal and

121 conjunctival surface [29-32]. Therefore, the criteria for designing the PP is dependent upon many

122 factors such as the purpose of application (tear retention or drug delivery), required length of

123 retention (short-term or long-term), patient compliance and/or commercial value. Interesting

124 examples of various PP designs were proposed by Eagle Vision, as shown in Figure 2. Here,

125 assorted PP designs have been engineered from silicone. Similarly, to enhance retention of PPs

126 in the puncta, SmartPLUG ${ }^{\mathrm{TM}}$ (Medenium, CA, USA) was developed. SmartPLUG ${ }^{\mathrm{TM}}$ is made

127 from biocompatible hydrophobic thermosensitive copolymer compositions of poly

128 (stearylmethacrylate) (SMA) with methylmethacrylate (MMA). These polymeric materials are

129 blended to form a composition, which has a glass transition temperature $\left(\mathrm{T}_{\mathrm{g}}\right)$ or melting

130 temperature $\left(\mathrm{T}_{\mathrm{m}}\right)$ at or below human body temperature $\left(37^{\circ} \mathrm{C}\right)$. SmartPLUG ${ }^{\mathrm{TM}}$ is a slender rod

131 that is solid at room temperature with a diameter of $0.4 \mathrm{~mm}$ and length of $9 \mathrm{~mm}$ prior to

132 insertion. After insertion into the ocular channel the diameter increases up to $1 \mathrm{~mm}$ and its length

133 decreases to $2 \mathrm{~mm}$. This expansion results in the adaptation and subsequent fixation of

134 SmartPLUG ${ }^{\mathrm{TM}}$ to the size and shape of a patient's punctum or canaliculum [18,33]. In another

135 attempt to improve patient tolerability of PPs, Form Fit ${ }^{\mathrm{TM}}$ intracanalicular plugs were developed.

136 Form Fit ${ }^{\mathrm{TM}}$ plugs are made of a hydrogel containing hydrophilic and hydrophobic domains. The

137 hydrogel is prepared by copolymerizing a hydrophilic monomer such as water-soluble $N$-vinyl 
138 carbazole with a hydrophobic monomer $N$-vinylpyrolidone derivative. The hydrogel expands 139 into a soft, pliable, gelatinous material after coming into contact with tear film. Form Fit ${ }^{\mathrm{TM}}$ plugs 140 absorb tear fluid and expand 20-times in volume after approximately $10 \mathrm{~min}$ of insertion, filling 141 and conforming to the size and shape of the vertical canaliculus [34,35].

142 PPs as controlled drug delivery implants

143 Since the introduction of PPs for the treatment of dry eyes by Freeman in 1975 [23], many

144 different types of PPs have been developed and are in widespread use. PPs have recently been

145 investigated for the controlled delivery of drugs to the tear fluid of the eye and the nasolacrimal 146 duct. PPs can offer numerous advantages over topical drug delivery such as reduction in loss of 147 drug and/or formulation owing to tear formation, reduction in lacrimal drainage of drug, ability 148 to achieve controlled drug delivery, patient compliance and possibly reduced costs.

149 Drug loading and drug release from PPs can be achieved in different ways (Figure 3). For 150 example, the drug can be loaded within the core of the PPs within the surrounding impermeable 151 layer: the drug essentially diffuses out from the cross-section which is in contact with tears 152 (Figure 3). Alternatively, pre-formed plugs can be coated with drug solution; however, 153 considering the dimensions of the PP, the quantity of drug coating might be limited owing to the 154 small surface area. Nevertheless, drug-releasing PPs not only improve the ability of drug to avoid 155 rapid clearance from the ocular surface but also release the drug into the ocular cavity for an 156 extended period of time.

157 The latanoprost PP delivery system (L-PPDS) was recently developed for controlled elution of 158 latanoprost for the treatment of open-angle glaucoma (OAG) and ocular hypertension $(\mathrm{OH})$. The 159 L-PPDS comprises a reservoir containing a polymeric blend of latanoprost which is housed in a 
$160 \mathrm{PP}$ and this reservoir has an opening through which drug will be released after coming into

161 contact with tear film. A $44 \mu \mathrm{g}$ L-PPDS has one-third the amount of drug in latanoprost eye

162 drops given continuously over three months [36]. L-PPDS recently completed a Phase II clinical

163 trial evaluating the safety, efficacy and dosing for the treatment of OAG and $\mathrm{OH}$ patients.

164 Results have indicated that L-PPDS showed positive efficacy trends with statistically and

165 clinically significant findings [37]. The PP device used in L-PPDS is also being investigated as a

166 platform to deliver the anti-allergy drug olopatadine for treatment of patients with allergic

167 conjunctivitis. Interim results from a Phase II proof-of-concept trial have shown that olopatadine

168 PP drug delivery system (O-PPDS) did not show significant difference in efficacy when

169 compared with placebo-PPDS with respect to reduction in the signs and symptoms of allergic

170 conjunctivitis [38]. The reason for the lack of efficacy of O-PPDS was reported to be due to the

171 environmental exposure chamber (EEC) model utilized in the trial not being sensitive enough to

172 demonstrate the potential benefit of the O-PPDS [39]. Latanoprost was initially loaded into

173 PLGA microspheres and incorporated into hydrogel-based PPs. The in vitro release profile of

174 latanoprost from PPs has shown that drug is released up to 90 days and the release profile is

175 dependent upon PLGA crosslinking and its chemical nature. Moreover, the PPs did not show any

176 initial burst release of latanoprost in any of the formulations [40].

177 Gupta and Chauhan reported a cyclosporine-A-releasing PP delivery system for treating dry 178 eyes. These PPs consisted of a cylindrical hydroxyl ethyl methacrylate (HEMA) cross-linked 179 with an ethyeneglycol dimethacrylate (EGDMA) core containing cyclosporine microparticles 180 covered by an impermeable silicone shell. Cyclosporine A was released for three months at a 181 zero-order rate of about $3 \mu \mathrm{g} /$ day [41]. The in vitro release studies have shown that PPs with 182 drug loading of $20 \%$ released drug at a rate of $3.5 \mu \mathrm{g} / \mathrm{day}$ for a period of one month without any 
183 initial burst release. The release was reasonably zero-order for the first ten days for these PPs.

184 However, the release was decreased when crosslinking of HEMA with EGDMA was increased 185 and the release profile was non-zero-order for the entire duration. An ocular pharmacokinetic 186 model was developed by performing a mass balance on the drug released into the ocular tear 187 film. This model predicted that the in vivo release of cyclosporine A from PPs is approximately $188 \quad 1.5 \mu \mathrm{g} /$ day with an ocular bioavailability of $64 \%$ [41].

189 In another study, PPs loaded with antibiotic moxifloxacin (MOX) were developed (Ocular 190 Therapeutix, MA, USA) for extended delivery of the drug for the treatment of bacterial 191 conjunctivitis. This PP comprises a dried polyethylene glycol hydrogel rod that is embedded with 192 MOX-encapsulated microspheres that release drug for ten days. The PPs released MOX at a 193 concentration greater than the target concentration of $250 \mathrm{ng} / \mathrm{ml}$, which is the target minimum 194 inhibitory concentration $\left(\mathrm{MIC}_{90}\right)$ up to ten days as calculated from mean tear fluid 195 concentrations. However, the concentrations of MOX were below detectable limits at day 20 and 196 day 30. A clinical study has reported that MOX-PPs were well tolerated, released and maintained 197 MOX tear fluid concentrations at therapeutic levels above the $\mathrm{MIC}_{90}$ values for seven days for 198 common susceptible conjunctivitis pathogens [42]. These studies clearly indicate the potential of 199 PPs for controlled delivery of drugs to the eye.

200 Chee assessed the safety and feasibility of a MOX-loaded PP in cataract patients. After cataract 201 surgery, MOX was inserted into the punctum and follow-up assessments were continued for 30 202 days. The study was conducted in two groups and each group consisted of ten cataract patients. It 203 was observed that the retention of MP in the punctum was $95 \%$ to day ten in 19 patients and all 204 plugs were absent at day 30 for both studies. MP was delivered and maintained drug 205 concentration in the tear fluid at therapeutic levels (above $250 \mathrm{ng} / \mathrm{ml}$ ) for seven days and 
206 exhibited a favorable safety and tolerability profile. It was concluded that it might be a viable

207 alternative to topical antibiotic drops for the treatment of bacterial conjunctivitis [42]. Ocular

208 Therapeutix conducted a single-site, single-armed, single-dose study using a pool of ten patients

209 and implanted a novel sustained drug delivery MOX-PP immediately following cataract surgery.

210 The patients were evaluated over a ten-day period. The MOX-PP achieved 100\% retention in all

211 ten patients and drug levels were maintained well above $\mathrm{MIC}_{90}(2000$ and $3000 \mathrm{ng} / \mathrm{ml})$. Hence,

212 the results demonstrated the sustained levels of MOX throughout the ten-day treatment period.

213 Furthermore, there were no adverse events and ocular complaints outside the normal post-

214 cataract symptoms [43].

215 Overall, drug-loaded PPs are potential devices for improved delivery of drugs to the ocular

216 cavity. Drugs that have poor ocular bioavailability can be loaded into PPs with a desired release

217 rate with significantly enhanced bioavailability. The polymeric composition of PPs can be

218 modified to obtain the desired release rate of a drug based on requirements of the disease

219 condition. Furthermore, a few studies have also reported combination of topical eye drops with

220 PPs that has resulted in enhanced drug delivery to the eye [44]. This clearly indicates the

221 overarching advantages of using PPs over conventional eye drop preparations that need frequent

222 dosing.

\section{Current challenges of using PPs}

224 Although PPs have demonstrated their advantages as drug delivery vehicles for the treatment of

225 DES, their use is associated with complications including mechanical conjunctivitis, plug 226 extrusion, spontaneous distal migration, epiphora, corneal abrasion, suppurative canaliculitis, 227 dacryocystitis and distal lachrymal system blockage [26,29]. In a study with silicone plugs (FCI 
228 Ophthalmics) spontaneous loss happened in $14.7 \%$ after three months, $27.3 \%$ after one year and

$22936.8 \%$ after two years [45]. In another study involving the modified Freeman 'tapered-shaft'

230 plug (Eagle Vision) and SoftPlug ${ }^{\mathrm{TM}}$ (OASIS Medical), it was reported that $47 \%$ spontaneous loss

231 occurred at six months with the majority being lost in the initial three months of the study [24].

232 The reasons for PP extrusion were attributed to mucosal dissection by the plug edges leading to

233 necrosed tissue and pyogenic granuloma formation [46]. Migration of the PP into the lacrimal

234 drainage system is another major complication that could require surgical intervention for

235 removal of the plug. The migrated plug can cause canaliculitis and dacryocystitis owing to a

236 local inflammatory reaction triggered by allergens and debris attracted by the negatively charged

237 surface of the silicone [47]. Complications such as punctal and proximal canalicular stenoses

238 after plug extrusion or migration were reported in a frequency of $25.7 \%$ during a period of 32

239 months [46]. In a separate study, canalicular stenosis occurred in $14.3 \%$ after three months,

$24026.9 \%$ after one year and $34.2 \%$ after two years [45].

241 Epiphora, which is the production of excessive tears, is another complication associated with use

242 of PPs. It was reported that mild epiphora occurs in up to $36 \%$ patients. Although most patients

243 tolerate the epiphora, up to 5\% request removal of the plugs [48]. Pyogenic granuloma leading to

244 plug extrusion was reported to occur for the silicone plug and SmartPLUG ${ }^{\mathrm{TM}}$. In a study

245 conducted in 404 patients with silicone PPs, pyogenic granuloma resulted in extrusion of $4.2 \%$ of

246 all plugs inserted after a median time of 141 days. Furthermore, large plug size was considered to

247 be the major risk factor leading to granuloma formation [47]. In a retrospective study of

248 SmartPLUG ${ }^{\mathrm{TM}}$ with 28 patients, $64.3 \%$ had canaliculitis, dacryocystitis or conjunctivitis [49]. A

249 more recent study with a total of 1026 patients receiving SmartPLUG ${ }^{\mathrm{TM}}$ was reported by Fezza et

250 al. [50]. According to the published results, the average time to develop canaliculitis after 
251 SmartPLUG ${ }^{\mathrm{TM}}$ insertion was 2.7 years with the lower left lid being the most common site,

252 followed by the right lower, right upper and left upper lids. The study reported a total of 61 cases

253 of SmartPLUG ${ }^{\mathrm{TM}}$-induced canaliculitis representing 6.0\% canaliculitis rate [50]. Overall, based

254 on results from clinical studies, the reasons for complications relating to PPs can be attributed to

255 effects of design, sizing and method of insertion.

\section{Concluding remarks}

257 PPs offer a safe and effective treatment for the patients with aqueous deficient dry eye and/or for

258 sustaining drug delivery to other conditions. The patients often benefit with symptomatic relief 259 and clinically measurable improvements. Therefore, this therapeutic approach can improve the 260 quality of life of many patients with severe conditions associated with the anterior segment of the 261 eye (e.g. dry eye or other infections). Careful selection of the optimal plug size and continuous 262 follow-up would be beneficial to maximize the success rate of the treatment. Based on the 263 progress achieved so far and the number of therapies in the pipeline, the future of PP-based dry 264 eye therapy or drug delivery seems optimistic. However, the experience and knowledge gained 265 from previous clinical studies will be helpful in overcoming many of the current drawbacks, so 266 that newer and effective PPs can be designed for simply blocking the puncta (for DES) and/or

267 sustaining drug delivery to the anterior segment of the eye. It is too early to comment on PP 268 application for posterior drug delivery. However, following successful demonstration of anterior 269 drug delivery, technologies such as specialized nanoparticle loaded PPs can be sought for long270 acting posterior drug delivery.

\section{Conflicts of interest}

272 The authors do not have any conflicts of interest to declare. 
274

275

276

277

278

279

280

281

282

283

284

285

286

287

288

289

290

291

292

293

294

295

296

297

298

299

300

301

302

303

304

305

306

307

308

309

310

311

312

313

314

\section{References}

1 Molokhia, S.A. et al. (2013) Anterior eye segment drug delivery systems: current treatments and future challenges. J. Ocul. Pharmacol. Ther. 29, 92-105

2 Ludwig, A. (2005) The use of mucoadhesive polymers in ocular drug delivery. Adv. Drug Deliv. Rev. 57, 1595-1639

3 Yu, J. et al. (2011) The economic burden of dry eye disease in the United States: a decision tree analysis. Cornea 30, 379-387

$4 \quad$ Fiscella, R.G. (2011) Understanding dry eye disease: a managed care perspective. Am. J. Manag. Care 17 (Suppl. 16), 432-439

5 Rein, D.B. et al. (2006) The economic burden of major adult visual disorders in the United States. Arch. Ophthalmol. 124, 1754-1760

6 Definition and Classification Subcommittee of the International Dry Eye WorkShop (2007) The definition and classification of dry eye disease. Ocul. Surf. 5, 75-92

7 Yao, W. et al. (2011) Dry eye syndrome: an update in office management. Am. J. Med. 124, 1016-1018

8 Dogru, M. and Tsubota, K. (2011) Pharmacotherapy of dry eye. Expert Opin. Pharmacother. 12, 325-334

9 Lemp, M.A. (1994) Management of the dry-eye patient. Int. Ophthalmol. Clin. 34, 101113

10 Pflugfelder, S.C. (1998) Advances in the diagnosis and management of keratoconjunctivitis sicca. Curr. Opin. Ophthalmol. 9, 50-53

11 Tavares Fde, P. et al. (2010) Dry eye disease. Semin. Ophthalmol. 25, 84-93

12 Macri, A. et al. (2000) A standardized visual scale for evaluation of tear fluorescein clearance. Ophthalmology 107, 1338-1343

13 Calonge, M. (2001) The treatment of dry eye. Surv. Ophthalmol. 45 (Suppl. 2), 227-239

14 Toda, I. et al. (1996) Hydroxypropyl methylcellulose for the treatment of severe dry eye associated with Sjogren's syndrome. Cornea 15, 120-128

15 Murube, J. et al. (1998) Classification of artificial tears. II: additives and commercial formulas. Adv. Exp. Med. Biol. 438, 705-715

16 Beetham, W.P. (1935) Filamentary keratitis. Trans. Am. Ophthalmol. Soc. 33, 413-435

17 Tabbara, K.F. (2007) Aspergillus fumigatus colonization of punctal plugs. Am. J. Ophthalmol. 143, 180-181

18 Burgess, P.I. et al. (2008) SmartPlug versus silicone punctal plug therapy for dry eye: a prospective randomized trial. Cornea 27, 391-394

19 Goto, E. et al. (2003) Improved functional visual acuity after punctal occlusion in dry eye patients. Am. J. Ophthalmol. 135, 704-705

20 Lemp, M.A. (1995) Report of the National Eye Institute/Industry Workshop on clinical trials in dry eyes. CLAO J. 21, 221-232

21 Foulds, W.S. (1961) Intra-canalicular gelatin implants in the treatment of keratoconjunctivitis sicca. Br. J. Ophthalmol. 45, 625-627 
22 Qiu, W. et al. (2013) Punctal plugs versus artificial tears for treating primary Sjogren's syndrome with keratoconjunctivitis SICCA: a comparative observation of their effects on visual function. Rheumatol. Int. 33, 2543-2548

23 Freeman, J.M. (1975) The punctum plug: evaluation of a new treatment for the dry eye. Trans. Sect. Ophthalmol. Am. Acad. Ophthalmol. Otolaryngol. 79, OP874-879

24 Balaram, M. et al. (2001) Efficacy and tolerability outcomes after punctal occlusion with silicone plugs in dry eye syndrome. Am. J. Ophthalmol. 131, 30-36

25 Kompella, U.B. et al. (2010) Recent advances in ophthalmic drug delivery. Ther. Deliv. 1, 435-456

26 Taban, M. et al. (2006) Update on punctal plugs. Compr. Ophthalmol. Update 7, 205212

27 Oasis dry eye products. Available at: http://oasismedical.com/dry-eye-products.html

28 FCI Ophthalmics dry eye products. Available at: http://www.fci-ophthalmics.com/dryeye-products

29 Bourkiza, R. and Lee, V. (2012) A review of the complications of lacrimal occlusion with punctal and canalicular plugs. Orbit 31, 86-93

30 Sheppard, J.D. (2003) Dry eye moves beyond palliative therapy. Manag. Care 12, 6-8

31 Sheppard, J.D. (2003) Guidelines for the treatment of chronic dry eye disease. Manag. Care 12, 20-25

32 Tai, M.C. et al. (2002) The clinical efficacy of silicone punctal plug therapy. Cornea 21, 135-139

33 Zhou, S.Q. (2001) Smart Ocular Plug Design and Method of Insertion for Punctal and Intracanalicular Implants. (Vol. 6234175B1) (Patent, U.S.), Medennium, Inc., Irvine, CA

34 Groves, N. (2005) New intracanalicular punctum plug relieves dry eye. Ophthalmology Times 30, 10

35 Christensen, J.M. (1992) Prosthesis with Improved Biocompatibility (Vol. 5,116,371)

36 Press release. Available at: http://www.qlinc.com/newsCenter/2009/090728a1.htm

37 Press release. Available at: http://www.qltinc.com/newsCenter/2012/121025.htm

38 Press release. Available at: http://www.qltinc.com/newscenter/documents/110209.pdf

39 Annual report. Available at: http://www.sec.gov/Archives/edgar/data/827809/000119312512075603/d293106d10k.ht $\mathrm{m}$

40 Sawhney, A.S. (2010) Drug Delivery Through Hydrogel Plugs US 2010/0209478 A1

41 Gupta, C. and Chauhan, A. (2011) Ophthalmic delivery of cyclosporine A by punctal plugs. J. Control. Release 150, 70-76

42 Chee, S.P. (2012) Moxifloxacin punctum plug for sustained drug delivery. J. Ocul. Pharmacol. Ther. 28, 340-349

43 Ocular Therapeutix (2010) Ocular therapeutix complete proof of principle study with moxifloxacin-loaded punctum plugs. Available at: http://www.ocutx.com/

44 Trattler, W.B. (2007) Combination therapy for dry eye: topical anti-inflammatory drops and punctal occlusion are an effective team. Ophthalmology Management. Available at: http://www.ophthalmologymanagement.com/articleviewer.aspx?articleID=100985

45 Horwath-Winter, J. et al. (2007) Long-term retention rates and complications of silicone punctal plugs in dry eye. Am. J. Ophthalmol. 144, 441-444 
46 Fayet, B. et al. (2001) Silicone punctal plug extrusion resulting from spontaneous dissection of canalicular mucosa: a clinical and histopathologic report. Ophthalmology $108,405-409$

47 Kim, B.M. et al. (2005) Pyogenic granulomas after silicone punctal plugs: a clinical and histopathologic study. Am. J. Ophthalmol. 139, 678-684

48 Kojima, K. et al. (2002) [Outcome of punctal plug occlusion therapy for severe dry eye syndrome]. Nihon Ganka Gakkai Zasshi 106, 360-364

49 SmartPlug Study Group (2006) Management of complications after insertion of the SmartPlug punctal plug: a study of 28 patients. Ophthalmology 113, 1859

50 Fezza, J.P. et al. (2011) The Medennium SMARTPlug may be associated with an increased incidence of canaliculitis. Review of Ophthalmology 11, 12

51 Available at: http://www.dryeye.org/plugs.htm

\section{Figure legends}

Figure 1. Schematic illustration of punctum location (inset) and placement of punctual plugs (PPs) in the punctum of the eye.

Figure 2. Schematic representation of assorted designs of silicone-based punctual plugs (PPs), where each design has been claimed to provide a unique advantage to the dry eye syndrome (DES) patients. (a) PLUG1 ${ }^{\mathrm{TM}}$ (CE marked) is a unique dual-lobed design that allows it to fit a wide range of punctum sizes. (b) SUPEREAGLE ${ }^{\circledR}$ (CE marked) design uses soft and low durometer silicone that claims to provide "super patient comfort". The tapered shaft and pivoting wide-flex nose design allows "super retention", available in three different sizes. (c) SUPERFLEX ${ }^{\circledR}$ is claimed to be a better fit design that is easier for insertion and provides greater patient comfort. This device is available in multiple sizes. (d) EAGLE FLEXPLUG ${ }^{\mathrm{TM}}$ is the only tapered shaft ${ }^{\mathrm{TM}} \mathrm{PP}$ with contouring traction ribs. This design is claimed to provide the ultimate in flexibility, fixation and patient comfort. (e) EAGLEPLUG ${ }^{\circledR}$ is an easy to insert and remove design [51].

Figure 3. Schematic illustration of a punctal plug delivery device.

\section{Table 1. List of different types of PPs that were fabricated in different shapes and from} different biodegradable and nonbiodegradable polymeric materials 
Highlights:

391

- Punctal plugs (PPs) are miniature medical devices that are used to block puncta to treat dry eye syndrome

392

- PPs are currently been investigated as sustained-release drug delivery devices

393 - Sustained-release PPs can be used to treat a range of anterior segment eye diseases

394 - Drug-loaded PPs showed improved ocular bioavailability when compared to eye drops

395 - PPs with nanoparticles can achieve drug delivery to the posterior segment of the eye

396

397 


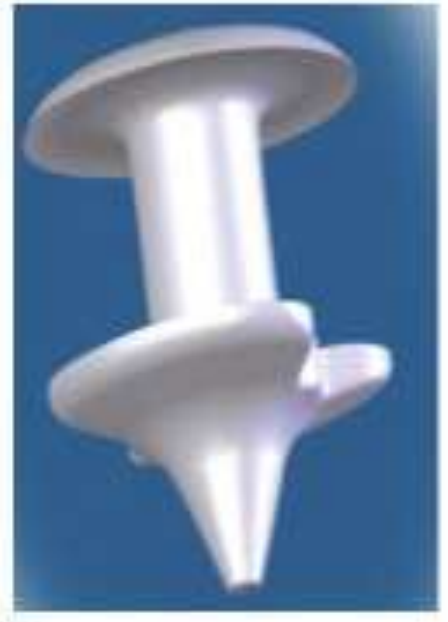

a

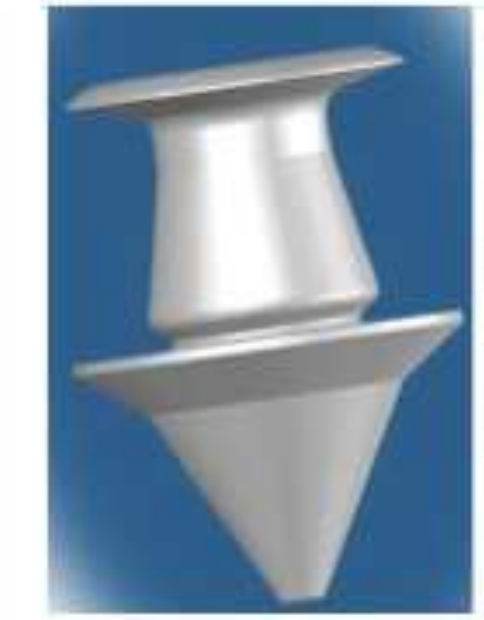

b

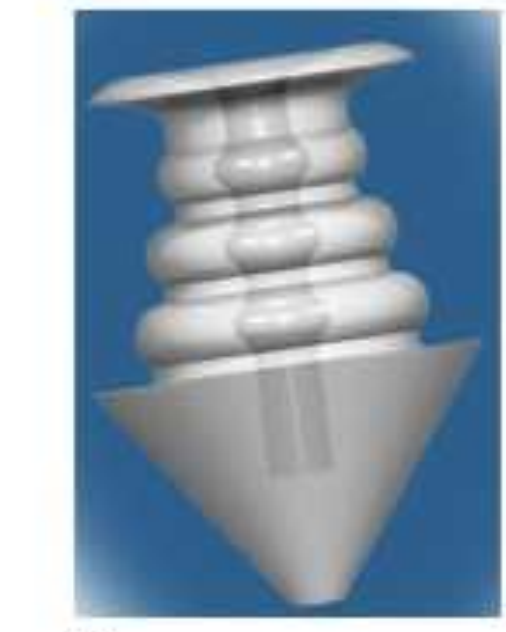

c

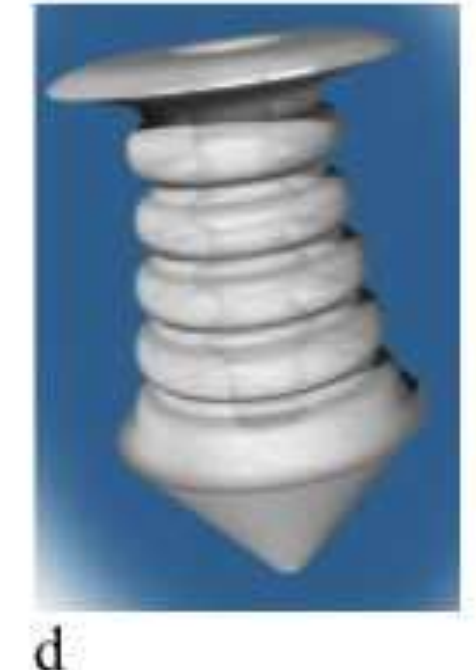

d

(

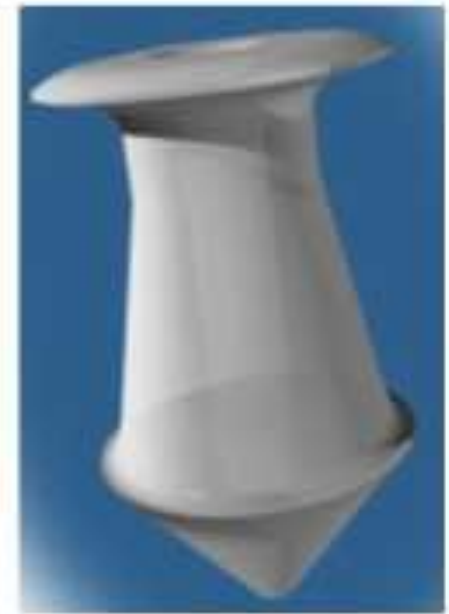

e

Figure 2

rage 1४ от 21

Figure 2

\section{Figu 2}

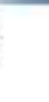




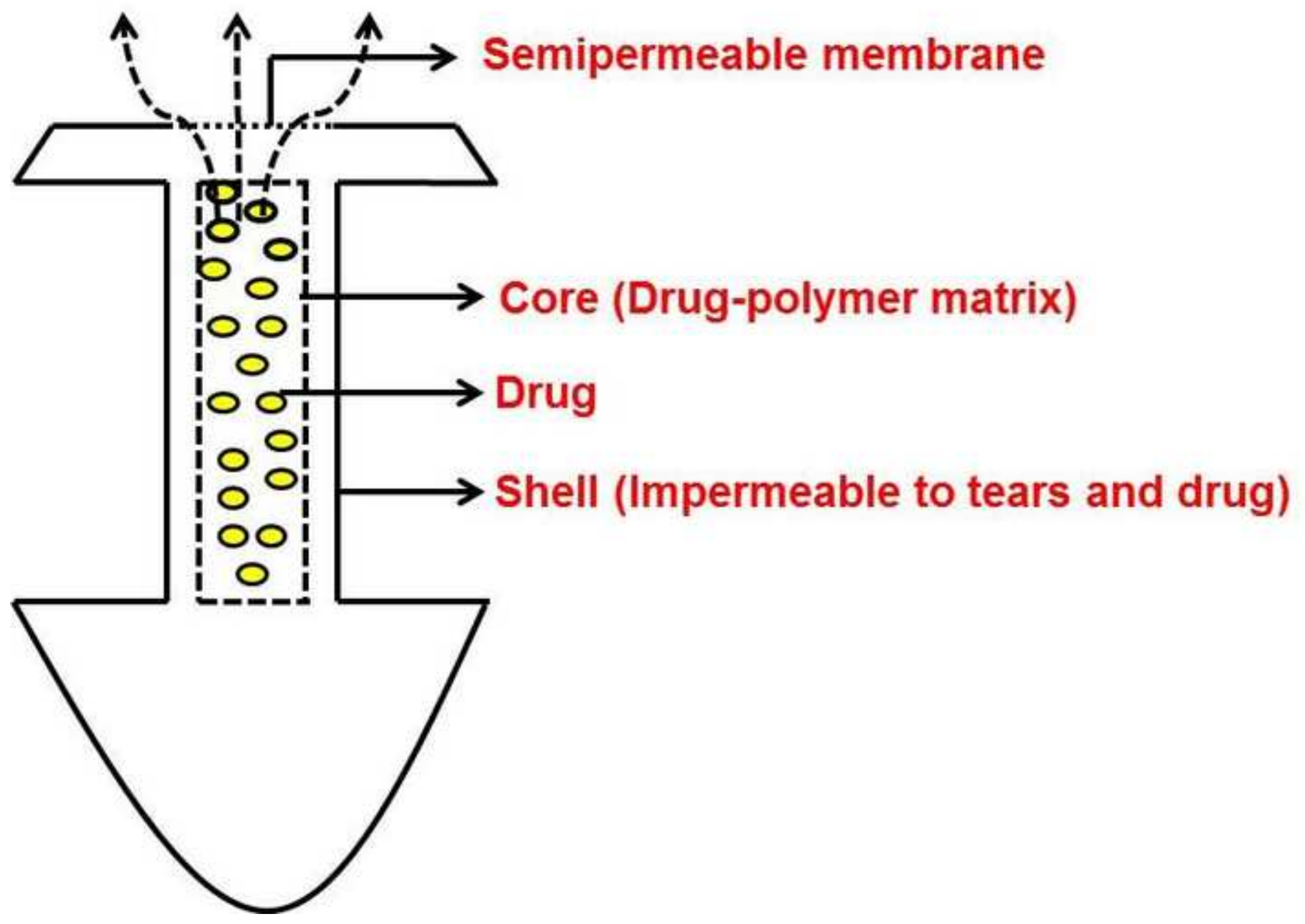


Table 1. List of different types of PPs that were fabricated in different shapes and from different biodegradable and non-biodegradable polymeric materials.

\begin{tabular}{|c|c|c|c|c|c|}
\hline Brand & Design & Dimensions & Composition & Application & Ref \\
\hline $\begin{array}{l}\text { SOFT PLUG } \\
\text { Collagen }\end{array}$ & Rod-shaped & $\begin{array}{l}2 \times 0.2 \mathrm{~mm}, 2 \times \\
0.3 \mathrm{~mm} \text { and } 2 \times \\
0.4 \mathrm{~mm}\end{array}$ & $\begin{array}{l}\text { Collagen. } \\
\text { Absorbable } \\
\text { within 2-5 days }\end{array}$ & $\begin{array}{l}\text { For short-term, } \\
\text { diagnostic, and } \\
\text { postsurgical occlusion. }\end{array}$ & [27] \\
\hline $\begin{array}{l}\text { SOFT PLUG } \\
\text { Silicone Plugs }\end{array}$ & $\begin{array}{l}\text { Pointed nose to allow } \\
\text { easy insertion with } \\
\text { large anchor with } \\
\text { wide shelf firmly } \\
\text { secures plug making } \\
\text { dislocation. }\end{array}$ & $\begin{array}{l}0.4,0.5 \text { and } 0.7 \\
\text { mm with } 0.8 \\
\text { mm diameter }\end{array}$ & $\begin{array}{l}\text { Medical grade } \\
\text { Silicone }\end{array}$ & $\begin{array}{l}\text { Control of tear drainage } \\
\text { through the canaliculus }\end{array}$ & [27] \\
\hline FORM Fit & Semi-rigid rod & $\begin{array}{l}0.3 \times 2.5 \mathrm{~mm} \\
0.3 \mathrm{~mm} \text { one size } \\
\text { fits all }\end{array}$ & $\begin{array}{l}\text { Polyvinyl } \\
\text { pyrrolidinone } \\
(\mathrm{PVP}) \text { based } \\
\text { Hydrogel. }\end{array}$ & $\begin{array}{l}\text { Hydrates over a } 10 \text { min } \\
\text { period. Upon contact } \\
\text { with } \\
\text { Tear fluid, the plug will } \\
\text { slowly swell to approx. } \\
3 \text { times its initial size to } \\
\text { completely fill the } \\
\text { vertical canalicular } \\
\text { cavity. }\end{array}$ & [27] \\
\hline $\begin{array}{l}\text { SOFT PLUG } \\
\text { Extended } \\
\text { Duration Plugs } \\
\text { [http://oasismed } \\
\text { ical.com/dry- } \\
\text { eye- } \\
\text { products.html] }\end{array}$ & Rod-shaped design & $\begin{array}{l}2 \times 0.2 \mathrm{~mm}, 2 \times \\
0.3 \mathrm{~mm}, 2 \times 0.4 \\
\mathrm{~mm}, \& 2 \times 0.5 \\
\mathrm{~mm}\end{array}$ & $\begin{array}{l}\text { Absorbable } \\
\text { copolymer of } \\
\text { glycolic acid } \\
\text { and trimethylene } \\
\text { carbonate and } \\
\text { dyed with D\&C } \\
\text { Green Number } \\
6 .\end{array}$ & $\begin{array}{l}\text { Block tear drainage. } \\
\text { Less than } 3 \text { months }\end{array}$ & [27] \\
\hline Snug Plugs ${ }^{\mathrm{TM}}$ & $\begin{array}{l}\text { Preloaded in a } \\
\text { stretched position, } \\
\text { returning to their } \\
\text { natural shape when } \\
\text { released in the } \\
\text { punctum }\end{array}$ & NA & $\begin{array}{l}\text { Medical grade } \\
\text { silicone }\end{array}$ & Dry eye & [28] \\
\hline Ready-Set" & Collarette plugs & $\begin{array}{l}0.4 \text { to } 1.0 \mathrm{~mm} \\
\text { diameter }\end{array}$ & $\begin{array}{l}\text { Medical grade } \\
\text { silicone }\end{array}$ & Dry eye & [28] \\
\hline
\end{tabular}

